\title{
Research on Teenagers' Sense of Social Responsibility Under the Background of Network Micro Era
}

\author{
Wenjuan Yan
}

\author{
Xi'an Siyuan University, Xi'an, 710038 \\ *Corresponding author.Email:525906718@qq.com
}

\begin{abstract}
With the widespread use of mobile terminal communication network $3 \mathrm{G}, 4 \mathrm{G}$ and the rapid development of personal internet devices such as smartphones, tablet computers, and so on, the era of micro-blog, WeChat, micro fiction has come, which deeply affects and changes the thinking, behavior and lifestyle of young students. As the main force of the micro era, young students shoulder the responsibility of forming the whole social moral responsibility. Young people's sense of social responsibility is not only related to personal development, social progress, the quality of the Chinese nation but also related to the prosperity of the country and the revitalization of the nation. How to cultivate young people's sense of social responsibility in the micro era is of great practical significance for building a socialist harmonious society and realizing the Chinese Dream of the great rejuvenation of the Chinese nation.
\end{abstract}

Keywords: Network micro era, sense of social responsibility, youth

\section{BACKGROUND}

First of all, with the rapid development of Internet technology, the era represented by WeChat and microblog is coming with the "micro" wind. Micro era refers to the era of information dissemination through a microblog, WeChat, micro-video and other new media represented by rich content and various forms of "micro" information. At present, teenagers who are willing to accept new things are the main participants in the "micro era". The mode of transmission of "micro" information is in line with the age characteristics and practical needs of contemporary teenagers and has become a way of life for them. Micro culture, with its convenience, super interactivity and other characteristics, has a subtle impact on young people's lives, especially in their learning environment. Therefore, under the background of micro-culture, it is of great theoretical and practical significance to strengthen the cultivation of teenagers' sense of social responsibility.

Secondly, in recent years, the party and the state have paid close attention to the sense of social responsibility of teenagers, increasingly emphasized the importance of teenagers' sense of social responsibility, vigorously advocated the promotion of teenagers' sense of social responsibility, and issued a series of relevant documents. For the first time, the eighteen Party of the Communist Party of China wrote: "cultivating students' sense of social responsibility" in the report of the Party Congress. In 2014, general secretary Xi Jinping proposed that the majority of young people should care about the state and learn to take social responsibility on the 54 youth day. The sense of social responsibility of teenagers has appeared many times in important national documents, which not only highlights its importance but also points out the direction of cultivation.
Finally, there is a gap between the current situation of teenagers' social responsibility and the actual requirements. General secretary Xi Jinping pointed out: "the quality and ability of youth directly affect the process of realizing China's dream." At present, teenagers' sense of social responsibility is generally good, and some of them are weakening. How to enhance the sense of social responsibility of young people, so that they actively participate in the practice of realizing the Chinese dream, to better improve themselves and promote social development, which is worthy of in-depth study.

\section{THE CONNOTATION OF TEENAGERS' SENSE OF SOCIAL RESPONSIBILITY}

Teenagers' sense of social responsibility refers to a value choice for teenagers to consciously fulfill and undertake their own and social responsibilities in the social environment, which can be divided from multiple levels, mainly divided into a value choice for themselves, the country, the society, the family, the collective and others. Social responsibility for oneself refers to the responsibility of teenagers for their own life, physical health, mental health, and mental health. The social responsibility for the country requires young people to be loyal to the motherland, identify with the culture, and take the prosperity and rejuvenation of the country as their social responsibility; the social responsibility for the society requires young people to do what they can for the coordinated development of the society; the social responsibility for the family means that young people should have the courage to bear the responsibility of the family, be filial to their parents, care for their families, and strive to create a harmonious society To create a better 
family living environment; to the social responsibility of the collective, young people are required to love the collective and obey the arrangement; to the social responsibility of others, young people are required to have a tolerant heart, be good at accepting others, and be willing to help others in their daily life.

\section{CHARACTERISTICS OF TEENAGERS' SOCIAL RESPONSIBILITY IN "MICRO ERA"}

\section{1. "micro era" Teenagers' Sense of Social Responsibility Beyond Time and Space}

The old way of cultivating teenagers' sense of social responsibility is limited by time and space. In the "micro era", microblog and WeChat software are widely used in teenagers' Ideological and political education and play an important role. They get rid of the constraints of cultivating teenagers' social responsibility in time and space to a great extent and provide a broader platform for teenagers.

\subsection{The Diversity of Teenagers' Sense of Social Responsibility in the "micro era"}

The traditional teaching work is mainly achieved through classroom teaching mode, boring teaching can not enhance students' attention and participation in the teaching content. In the "micro era", there are various ways of information dissemination. At first, relying on a microblog to disseminate information is no longer the only way. With the emergence of various forms of application platforms in the "micro era", whether in the way of education or the content, they provide reliability for the cultivation of innovative youth's sense of social responsibility.

\subsection{The Disordered Interaction of Teenagers' Sense of Social Responsibility in the "micro era"}

The educational interaction between teachers and students is a difficult problem for educators. Most of the old educational models are crammed into students in the classroom, which will completely ignore the dominant position and acceptance ability of teenagers, and easily make them have a negative mentality. The disordered interaction of the "micro era" creates an equal communication, relaxed and pleasant learning environment for teenagers, which will enable teenagers to freely choose and obtain the information they want, improve their enthusiasm and participation to a certain extent, and make the relationship between teachers and students closer.

\subsection{Information Diversification of Teenagers' Social Responsibility in "micro era"}

The diversified development of information in the "micro era" has brought new opportunities for the cultivation of teenagers' sense of social responsibility. The sources of information have become more extensive, and it also provides a good platform for teenagers to show themselves.

\section{PROBLEMS IN THE CULTIVATION OF TEENAGERS' SENSE OF SOCIAL RESPONSIBILITY UNDER THE BACKGROUND OF THE "MICRO ERA"}

\subsection{Separation of Social Responsibility in Virtual Space from that in Reality}

In the traditional sense, practice is the most effective way to cultivate a sense of social responsibility. Due to the continuous progress of the times, the changes brought about by the "micro era" have a profound impact on teenagers. At present, we have begun to pay attention to the social responsibility education of virtual space in the "micro era", and have done some work, but we ignore to integrate the social responsibility education of virtual space with the real social responsibility education. Some fine traditions of social responsibility in real society are not well inherited and carried forward by the sense of social responsibility in virtual space, which leads to the separation of the two

\subsection{The Consciousness and Behavior of Teenagers' Social Responsibility are Inconsistent}

Although many teenagers have a sense of social responsibility, they have not paid practical action. "Micro era" provides a variety of micro platforms, so that young people can freely express their opinions on current events in society on these platforms. But many teenagers are only active in the micro platform. In real life, they don't put into practice what they have said on the micro platform, and they don't take action for their sense of social responsibility.

\subsection{Teenagers' Consciousness of Fulfilling Social Responsibility is Poor}

After entering university life, some teenagers feel that they are free from anyone's bondage and no longer strive to make progress in their studies, and they have no long-term plans for their study career and life planning. Some students who are not determined begin to indulge 
themselves and lower their requirements. For some college students who are not strong in self-control, they are not willing to fulfill their social responsibility, which affects the formation of their sense of social responsibility.

\section{THE COUNTERMEASURES OF CULTIVATING TEENAGERS' SENSE OF SOCIAL RESPONSIBILITY UNDER THE BACKGROUND OF MICROCULTURE}

\subsection{Promote the Construction of a "three in one" Environment and Deepen the Cognition of Teenagers' Social Responsibility}

"Three" refers to the country, society, and family, and "one" refers to the youth themselves. Through the environmental construction of the country, society, and family, teenagers can deepen their understanding of social responsibility in a strong atmosphere, and internalize it into their ideas and externalize it into behavior.

From the national level, we should optimize the democratic political environment, increase investment in education, and improve the construction of relevant laws and regulations. The government should increase the investment in education, especially in the ideological and political education of teenagers. We must further strengthen the legal construction, restrict the bad behavior, and increase the punishment.

From the social level, we should create a good public opinion environment, optimize the network media environment, and optimize the social and cultural environment. The government should strengthen the supervision of network operators and improve the quality of cultural products. To strengthen the concept of guidance, through various ways and methods to strengthen the attention of young people to the sense of social responsibility.

From the family level, parents should highlight the sense of responsibility education, create a good family atmosphere, pay attention to the stage of children's physical and mental development, improve their selfcultivation and set an example.

\subsection{Establish a New Mode of Cultivating School Social Responsibility Consciousness in the "micro era"}

Build and supervise the school official "micro platform". Schools should comply with the development trend of the "micro era" and actively create a "micro platform" in Colleges and universities. Strengthen the interaction between educators and students to convey healthy and upward values.

Adhere to the education of socialist core values. Taking the socialist core values as the starting point, we should highlight the content of responsibility training and strengthen the teenagers' cognitive ability of responsibility. Establish a "micro-community" of youth volunteer service. Youth volunteer service activities can not only show their self-worth but also feel happy in helping others, which is an important means of practicing social responsibility.

\subsection{Strengthen the Self-Education Ability of Teenagers}

Improve self-awareness. To strengthen their sense of social responsibility, we need to have a correct understanding of ourselves, clarify their role in society, correctly understand the relationship between individuals and society, and constantly reflect on whether their behaviors and thoughts meet the needs of society.

We should abide by laws and moral standards and strengthen self-discipline. Consciously use laws, disciplines, rules, and regulations, and moral norms to restrain themselves, regulate and control their words and deeds, and strengthen the consciousness of self-restraint. Develop good behavior habits, change the mental outlook, have a healthy mind, improve subjective initiative, consciously strengthen the education of cultivating a sense of responsibility.

\section{CONCLUDING AND DISCUSSIONS}

As excellent talents, teenagers are the future and hope of the motherland. It is their bounden duty to maintain the long-term stability of the country and the good development of the society. Therefore, the cultivation of teenagers' sense of social responsibility is particularly important. In the "micro era", we should pay attention to the integration of family, school, and society, to provide a broader space for the cultivation and shaping of teenagers' sense of social responsibility.

This paper starts from the definition of "micro era", elaborates and analyzes the basic meaning of "micro era", and analyzes the era characteristics of teenagers' sense of social responsibility in the "micro era" from the four aspects of super time and space, diversity, disordered interaction and information diversification. Starting from the characteristics of the times, this paper finds out the problems existing in the sense of social responsibility of teenagers in the "micro era" and analyzes the reasons. On this basis, it can better innovate the ways to cultivate the sense of social responsibility of teenagers in the "micro era". For the overall grasp of the cultivation carrier of teenagers' sense of social responsibility in the "micro era", we should closely focus on the word "micro" and combine it with the "micro" characteristics of the micro era, to integrate it into the cultivation process of teenagers' sense of social responsibility. 


\section{ACKNOWLEDGMENT}

This work is sponsored by the research project of the "Special scientific research project" by the Education Department of Shaanxi Provincial Government. Project No.: 20JK0304

This work is also sponsored by the research project of Shaanxi Social Science Fund: Research on the Social Responsibility of Shaanxi internet media under Major Emergencies” , Project No.: 2020R040

\section{REFERENCES}

[1] Xinwen Bi, Liang Zhang, Yiqun Yang, Wenxin Zhang. Parenting Practices, Family Obligation, and Adolescents' Academic Adjustment: Cohort Differences with Social Change in China [J]. Journal of Research on Adolescence, 2020, 30(3).

[2] Rose M A,Barker M,Liese J,Adams O,Ankermann T,Baumann U,Brinkmann F,Bruns R,Dahlheim M,Ewig S,Forster J,Hofmann G,Kemen C,Lück C,Nadal D,Nüßlein T,Regamey N,Riedler J,Schmidt S,Schwerk N,Seidenberg J,Tenenbaum T,Trapp S,van der Linden M. [Guidelines for the Management of Community Acquired Pneumonia in Children and Adolescents (Pediatric Community Acquired Pneumonia, pCAP) Issued under the Responsibility of the German Society for Pediatric Infectious Diseases (DGPI) and the German Society for Pediatric Pulmonology (GPP)].[J]. Pneumologie (Stuttgart, Germany), 2020, 74(8).

[3] Park Heejung, Weiss Bahr, Trung Lam T., Ngo Victoria K., Lau Anna S. Adolescents' family obligation and activities in rural and urban Vietnam: Implications for social change $[\mathrm{J}]$. International Journal of Psychology, 2020, 56(1).

[4] Park Heejung, Weiss Bahr, Trung Lam T, Ngo Victoria K, Lau Anna S. Adolescents' family obligation and activities in rural and urban Vietnam: Implications for social change.[J]. International journal of psychology: Journal international de Psychologie, 2020.

[5] Bi Xinwen, Zhang Liang, Yang Yiqun, Zhang Wenxin. Parenting Practices, Family Obligation, and Adolescents' Academic Adjustment: Cohort Differences with Social Change in China.[J]. Journal of research on adolescence: the official journal of the Society for Research on Adolescence, 2020.
[6] E. Kay M. Tisdall. Conceptualizing children and young people's participation: examining vulnerability, social accountability, and co-production $[\mathrm{J}]$. The International Journal of Human Rights, 2017, 21(1).

[7] Yeo J D. Devastating injury in adolescents: does society have a responsibility to the victims?[J]. Australian family physician, 1983, 12(4). 